\title{
Population genetic structure of hard clam (Meretrix lyrata) along the Southern coast of Thailand
}

\author{
JUTHAMAS SUPPAPAN ${ }^{1}$, PRADIT SANGTHONG ${ }^{2}$, APIRAK SONGRAK ${ }^{3}$, VERAKIAT SUPMEE ${ }^{4, \vartheta}$ \\ ${ }^{1}$ Education in Science Program, Faculty of Education, Nakhon Si Thammarat Rajabhat University. Mueang Nakhon Si Thammarat District, Nakhon Si \\ Thammarat, 80280, Thailand \\ ${ }^{2}$ Department of Genetics, Faculty of Science, Kasetsart University. 50 Paholyothin Road, 10900, Bangkok, Thailand \\ ${ }^{3}$ Department of Fishery Technology, Faculty of Science and Fishery Technology, Rajamangala University of Technology Srivijaya. Sikao District, Trang, \\ 92150, Thailand \\ ${ }^{4}$ Department of Science, Faculty of Science and Technology, Rajamangala University of Technology Srivijaya. Thungsong District, Nakhon Si \\ Thammarat, 80110, Thailand. Tel./fax.: +66-75-773336, `email: verakiat.s@rmutsv.ac.th
}

Manuscript received: 9 March 2021. Revision accepted: 8 April 2021.

\begin{abstract}
Suppapan J, Sangthong P, Songrak A, Supmee V. 2021. Population genetic structure of hard clam (Meretrix lyrata) along the Southern coast of Thailand. Biodiversitas 22: 2489-2496. The hard clam (Meretrix lyrata), which is an economically important fishery item in Southern Thailand, has decreased rapidly due to overexploitation. To construct sustainable management of this species, genetic information is necessary. In our study, the genetic diversity of $M$. lyrata was investigated based on the variation of the nucleotide sequence (439 bp) of mitochondrial DNA (mtDNA) in the cytochrome oxidase subunit I gene (mtDNA COI). The mtDNA COI sequences of 145 individuals collecting from 6 sampling sites along the Southern coast of Thailand were analyzed. The results revealed that M. lyrata populations showed moderate to low levels of genetic diversity. All of the population genetic structure analysis revealed the genetic differentiation of the hard clam between the Gulf of Thailand and the Andaman Sea populations. Based on these results, a genetic structure of the hard clam M. lyrata in Southern Thailand was possibly caused by a disruptive gene flow from the geographic factors by the ThaiMalay Peninsula. The demographic history test revealed that the hard clam living in Southern Thailand had experienced population expansion. This study provided the first genetic information that could be used for conserving the hard clam M. lyrata in Southern Thailand.
\end{abstract}

Keywords: Clam, demographic history, genetic diversity, mitochondrial DNA, Thailand

\section{INTRODUCTION}

The hard clam (Meretrix lyrata) is a bivalve belonging to the family Veneridae. This species is widely distributed in the Indo-West Pacific (Idris et al. 2017). In Thailand, it lives in estuarine areas in sand and mud (Hamli et al. 2017) along the Gulf of Thailand and the Andaman Sea coast. It is a valuable resource in the estuarine environment of Thailand that local fishermen can earn their livings for a long time. It has economic value and is sold at the fresh market with a price range of 50 to 100 Baht per kilogram. However, the change from traditional harvesting to mechanical harvesting may put the hard clam at the risk of extinction.

Population genetics structure is the study of patterns of genetic diversity within and among populations. Gene flow is a factor that maintains genetic diversity, and is indicated with population fitness (Cheng et al. 2020). Fragmentation of habitat leads to reduce gene flow among populations and population genetic structure (Schlaepfer et al. 2018). Therefore, understanding the genetic structure is necessary for the conservation of marine organisms. Southern coast of Thailand is located between two seas, divided into east coast (Gulf of Thailand) and the west coast (Andaman Sea) by geographic barriers from the Thai-Malaysian peninsula. This geographic barrier disrupts the gene flow of marine animals within two seas, and affects the genetic structure in several organisms such as spotted scat (Scatophagus argus) (Supmee 2015), oceanic paddle crab (Varuna literata) (Suppapan et al. 2017), and threadfin bream (Nemipterus hexodon) (Supmee and Suppapan 2020).

Molecular genetic techniques contribute to the characterization of the population genetic structure of marine species. The mitochondrial DNA (mtDNA) sequencing has been proven to be robust tools for detecting population fragmentation (Zarei and Alipanah 2014). Its unique features are, e.g. haploidy, maternal transmission, high copy number per cell, absence from intermolecular recombination, and rapid mutation rate (Ma et al. 2011). Cytochrome oxidase subunit I gene (mtDNA COI) has been extensively used for studies regarding population genetic structure, phylogeography, and demographic history of various marine species (Guo et al. 2012), such as Indian oil sardine (Sardinella longiceps) (Sukumaran et al. 2016), small yellow croaker (Larimichhys polyacis) (Zhang et al. 2017), and sea bass (Lateolabrax maculates) (Wang et al. 2017a). In this study, the information of the mtDNA COI sequence was used to discuss the following questions: (i) to observe the population genetic structure of the hard clam $M$. lyrata and (ii) to detect demographic changes in natural populations of $M$. lyrata inhabiting the coastline of Southern Thailand. The genetic information of local populations is useful for maintaining genetic diversity 
and increasing the population size of the natural stock to achieve the goal of sustainable exploitation of this clam.

\section{MATERIALS AND METHODS}

\section{Sampling sites and DNA extraction}

One hundred and forty-five hard clams Meretrix lyrata were caught by hand from 6 sampling sites within fishing grounds along with the south of Thailand coast, including Chumporn, Surat Thani, Nakhon Si Thammarat, Satun, Trang, and Phang Nga Province (Figure 1) during December 2017 to October 2018 (Table 2, Figure 1). Specimens were preserved in ice, transported to a laboratory, and stored at $-20{ }^{\circ} \mathrm{C}$ until DNA extraction. Total genomic DNA was extracted from muscle tissue using the Genomic DNA Extraction Kit (Tiangen BioTech, Beijing, China) according to the manufacturer specifications.

\section{PCR amplification and nucleotide sequencing}

A fragment of the mtDNA COI gene was amplified using the primer ML_COI_H1: 5' GCA GCT AAT ACA GGC ATA GCA 3' and ML_COI_L1: 5' GGG CTG GTC TAG TTG GTA CG 3'. Polymerase chain reaction (PCR) was carried out in $50 \mu \mathrm{l}$ reaction mixture containing 50-100 ng template DNA $5 \mu \mathrm{l}, 10 \mathrm{X}$ Taq buffer $5 \mu \mathrm{l}, 25 \mathrm{mM}$ $\mathrm{MgCl}_{2} 5 \mu \mathrm{l}, 2 \mathrm{mM}$ dNTPs mix $4 \mu \mathrm{l}, 10 \mu \mathrm{M}$ each primers 2 $\mu 1,2.5$ unit Taq DNA polymerase (ThermoSCIENTIFIC, MA, USA) $0.5 \mu \mathrm{l}$, and $26.5 \mu \mathrm{l}$ of $\mathrm{ddH}_{2} \mathrm{O}$. Amplification was performed in a thermocycler (Major Cycler, CYCLER, Taoyuan, Taiwan). The thermal cycle for PCR was $94^{\circ} \mathrm{C}$ at $4 \mathrm{~min}$ for the first denaturation, 35 cycles consisting of $94^{\circ} \mathrm{C}$ at $40 \mathrm{sec}$ for denaturation, $56^{\circ} \mathrm{C}$ at $1 \mathrm{~min}$ for annealing, $72^{\circ} \mathrm{C}$ at $1 \mathrm{~min}$ for the extension, and a final extension at $72^{\circ} \mathrm{C}$ for $10 \mathrm{~min}$. All PCR products were separated on $1 \%$ agarose gels $(1 \times \mathrm{TAE})$ for $45 \mathrm{~min}$ at 100 $\mathrm{V}$, stained with ethidium bromide, and visualized under UV light to verified product band size. The correct size of the PCR product was purified using a DNA product purification kit (Tiangen BioTech, Beijing, China) and sequenced ( $1^{\text {st }}$ Base Laboratory, Selangor, Malaysia).

\section{Data analysis}

Genetic diversity

Sequences were viewed and edited to 439 base pairs. All sequences were confirmed with BLAST searches in GenBank and aligned using ClustalW version 1.83 (Thompson et al. 1994). The genetic diversity consisting of the polymorphic sites, nucleotide diversity $(\pi)$, and haplotype diversity $(h)$ was calculated using the DnaSP version 6.00 (Rozas et al. 2017).

\section{Population genetic structure}

An analysis of molecular variance (AMOVA) was performed to investigate the population genetic structure of the hard clam implemented in ARLEQUIN v. 3.5 (Excoffier and Lischer 2010). We conducted AMOVA into two putative structures. Firstly, the hard clams $M$. lyrata samples were separated into six populations according to the sampling areas (Chumporn, Surat Thani,
Nakhon Si Thammarat, Satun, Trang, and Phang Nga). Secondly, samples from Chumporn, Surat Thani, and Nakhon Si Thammarat were considered as the Gulf of Thailand, while those from Satun, Trang, and Phang Nga were grouped as the Andaman Sea. A hierarchical analysis of molecular variance was performed with 10,000 permutations $(p<0.05)$. We calculated pairwise $F_{S T}$ as implemented in ARLEQUIN v. 3.5 (Excoffier and Lischer $2010)$ with 10,000 permutations $(p<0.05)$ to analyze differentiation among populations. The neighbor-joining (NJ) method based on the matrix of Kimura 2-parameter distance implemented in MEGA version 7.0 (Kumar et al. 2016) was used to construct a phylogenetic tree. The statistical robustness of the tree topology was obtained by bootstrapping using 1000 replicates. A minimum spanning network (MSN) was constructed to depict the relationship among haplotypes using ARLEQUIN v. 3.5 (Excoffier and Lischer 2010) and drawn by hand.

\section{Demographic history}

Historical demographic patterns of the hard clam were examined with three methods. In the first method, the neutrality test was estimated. We calculated Fu's Fs (Fu 1997) and Tajima's $D$ (Tajima 1989) in ARLEQUIN v. 3.5 (Excoffier and Lischer 2010) with 10,000 permutations $(p<0.05)$ to test for demographic expansion. In the second method, the estimated demographic model was tested by the Harpending raggedness index (Grant 2015) and the sum of squared deviations (SSD) between observed and expected mismatch distribution with 10,000 bootstrap replicates, as implemented in ARLEQUIN v. 3.5(Excoffier and Lischer 2010). In the third method, two parameters: $\theta_{0}$ (population size before expansion, $\theta_{0}=2 N_{0} \mu$ ) and $\theta_{1}$ (population size after expansion, $\theta_{l}=2 N_{l} \mu$ ) of the mismatch distribution were calculated.

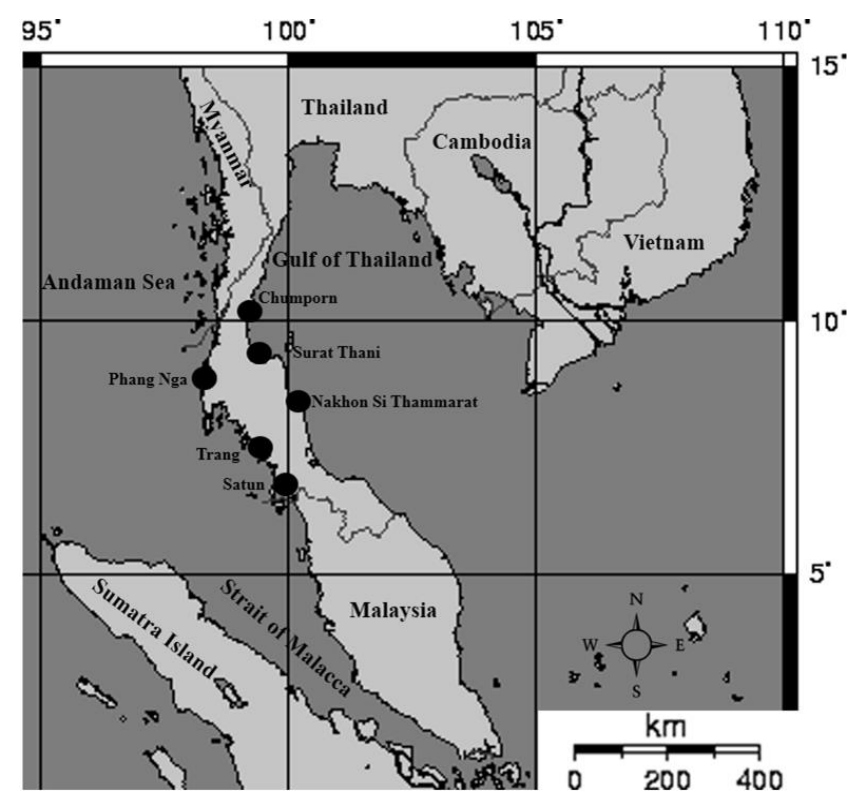

Figure 1. Map showing sampling locations of the hard clam Meretrix lyrata populations along the Southern coast of Thailand 


\section{RESULTS AND DISCUSSION}

\section{Genetic diversity}

The alignment results showed that out of 439 aligned sites comprising 11 polymorphic sites and defined 6 haplotypes (Table 1). Haplotype diversity and the nucleotide diversity value of the Southern Thailand population was $0.581 \pm 0.020$ and $0.00840 \pm 0.00013$, the Gulf of Thailand population was $0.029 \pm 0.028$ and $0.00007 \pm 0.00006$, and the Andaman Sea population was $0.263 \pm 0.064$ and $0.00063 \pm 0.00016$ (Table 2). In total, six haplotypes were identified, consisting of 4 shared (HAP 01, HAP 02, HAP 03, HAP 05) and two rare haplotypes (HAP 04, HAP 06) (Table 3). Haplotype HAP 01 was shared by all populations from the Andaman Sea, and haplotype HAP 05 was shared by all populations from the Gulf of Thailand. Haplotype HAP 04 and HAP 06 were unique haplotypes (private haplotype) (Table 3). Chumporn and
Trang populations possessed one private haplotype HAP 04 and HAP 06, respectively (Table 3 ).

\section{Population genetic structure}

Based on the mtDNA COI sequence of the hard clam collected from the Southern Thailand coast, the genetic structure of this species was separated into the Gulf of Thailand and the Andaman Sea population. As the first piece of evidence, the AMOVA showed that the hard clam population along the Southern coast of Thailand was statistically significant $\left(\Phi_{S T}=0.964, p=0.000\right)$. Besides, the genetic structure analysis between the Gulf of Thailand and the Andaman Sea was significantly different $\left(\Phi_{C T}=\right.$ $0.977, p=0.037$ ) (Table 4). The second evidence, pairwise $F_{S T}$ between the Gulf of Thailand and the Andaman Sea population showed significant differences for most comparison. The genetic differentiation within the sampling sites was presented in Table 5.

Table 1. Variation position among 6 mtDNA COI haplotypes of the hard clam Meretrix lyrata from the six sampling sites along the Southern Thailand coast. All haplotypes are compared with haplotype HAP 01. Dot indicates identical nucleotides

\begin{tabular}{|c|c|c|c|c|c|c|c|c|c|c|c|}
\hline \multirow{2}{*}{ Haplotype } & \multicolumn{11}{|c|}{ Nucleotide position } \\
\hline & 27 & 110 & 113 & 128 & 176 & 196 & 215 & 254 & 360 & 402 & 415 \\
\hline HAP 01 & $\mathrm{~A}$ & $\mathrm{G}$ & A & $\mathrm{G}$ & $\mathrm{A}$ & A & $\mathrm{T}$ & A & $\mathrm{A}$ & A & A \\
\hline HAP 02 & . & . & . & . & . & . & $\mathrm{C}$ & . & . & . & . \\
\hline HAP 03 & . & . & . & . & G & . & . & . & . & . & . \\
\hline HAP 04 & . & . & . & . & . & . & . & . & $\mathrm{C}$ & . & . \\
\hline HAP 05 & G & A & . & A & . & G & . & $\mathrm{G}$ & . & $\mathrm{G}$ & $\mathrm{G}$ \\
\hline HAP 06 & $\mathrm{G}$ & $\mathrm{A}$ & $\mathrm{G}$ & A & . & $\mathrm{G}$ & 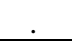 & $\mathrm{G}$ & & $\mathrm{G}$ & $\mathrm{G}$ \\
\hline
\end{tabular}

Table 2. Genetic diversity in mtDNA COI of the hard clam Meretrix lyrata from the six sampling sites along the Southern Thailand coast

\begin{tabular}{|c|c|c|c|c|c|}
\hline Collecting location & $N$ & $\begin{array}{c}\text { No. polymorphic } \\
\text { sites }\end{array}$ & No. haplotypes & $\begin{array}{c}\text { Haplotype diversity }(h) \\
(\text { mean }+ \text { SD) }\end{array}$ & $\begin{array}{c}\text { Nucleotide diversity }(\pi) \\
(\text { mean } \pm \text { SD })\end{array}$ \\
\hline Chumporn & 23 & 1 & 2 & $0.087 \pm 0.078$ & $0.00020 \pm 0.00018$ \\
\hline Surat Thani & 22 & 0 & 1 & $0.000 \pm 0.000$ & $0.00000 \pm 0.00000$ \\
\hline Nakhon Si Thammarat & 24 & 0 & 1 & $0.000 \pm 0.000$ & $0.00000 \pm 0.00000$ \\
\hline Satun & 25 & 1 & 2 & $0.280 \pm 0.101$ & $0.00064 \pm 0.00023$ \\
\hline Trang & 26 & 3 & 4 & $0.403 \pm 0.113$ & $0.00100 \pm 0.00031$ \\
\hline Phang Nga & 25 & 1 & 2 & $0.080 \pm 0.072$ & $0.00018 \pm 0.00086$ \\
\hline Gulf of Thailand & 69 & $\mathbf{1}$ & 2 & $0.029 \pm 0.028$ & $0.00007 \pm 0.00006$ \\
\hline Andaman Sea & 76 & 3 & 4 & $0.263 \pm 0.064$ & $0.00063 \pm 0.00016$ \\
\hline Southern Thailand & 145 & 11 & 6 & $0.581+0.020$ & $0.00840+0.00013$ \\
\hline
\end{tabular}

" $N$ " indicates number of individuals per sampling site

Table 3. The frequency and mtDNA COI haplotype distributions of the hard clam Meretrix lyrata from the six sampling sites along the Southern Thailand coast

\begin{tabular}{lcccccc}
\hline Haplotype & Chumporn & Surat Thani & Nakhon Si Thammarat & Satun & Trang & Phang Nga \\
\hline HAP 01 & - & - & - & 21 & 20 & 24 \\
HAP 02 & - & - & - & 4 & - & 3 \\
HAP 03 & - & - & - & - & 1 & - \\
HAP 04 & - & - & 24 & - & - & - \\
HAP 05 & 22 & - & - & - & - & 26 \\
HAP 06 & 1 & 22 & 24 & 25 & 25 \\
Total & 23 & &
\end{tabular}


Table 4. Analysis of molecular variance (AMOVA) results for the hard clam Meretrix lyrata from the six sampling sites along the Southern Thailand coast

\begin{tabular}{lccccc}
\hline \multicolumn{1}{c}{ Source of variation } & df & $\begin{array}{c}\text { Sum of } \\
\text { squares }\end{array}$ & $\begin{array}{c}\text { Variance } \\
\text { components }\end{array}$ & $\begin{array}{c}\text { Percentage of } \\
\text { variation }\end{array}$ & $\boldsymbol{p}$-value \\
\hline Single region & & & & & \\
$\quad$ Among populations & 5 & 254.048 & $2.100 \mathrm{Va}$ & 96.45 & $\Phi_{S T}=0.964^{*}(p=0.000)$ \\
$\quad$ Within populations & 139 & 10.738 & $0.077 \mathrm{Vb}$ & 3.55 & \\
$\quad$ Total & 144 & 264.786 & 2.177 & & \\
Gulf of Thailand and Andaman Sea & & & & & \\
$\quad$ Among groups & 1 & 253.498 & $3.502 \mathrm{Va}$ & 97.77 & $\Phi_{C T=0.977^{*}(p=0.037)}$ \\
Among populations within groups & 4 & 0.550 & $0.002 \mathrm{Vb}$ & 0.07 & $\Phi_{S C}=0.031(p=0.082)$ \\
Within populations & 139 & 10.738 & $0.077 \mathrm{Vc}$ & 2.16 & $\Phi_{S T}=0.000^{*}(p=0.000)$ \\
$\quad$ Total & 144 & 264.786 & 3.582 & & \\
\hline
\end{tabular}

Note: *significant differentiation $(p<0.05)$

Table 5. Pairwise $F_{S T}$ values among the six populations of the hard clam Meretrix lyrata collecting from the Southern Thailand coast

\begin{tabular}{|c|c|c|c|c|c|c|c|}
\hline \multirow[b]{2}{*}{ Site } & & \multicolumn{3}{|c|}{ Gulf of Thailand } & \multicolumn{3}{|c|}{ Andaman Sea } \\
\hline & & Chumporn & Surat Thani & $\begin{array}{c}\text { Nakhon Si } \\
\text { Thammarat }\end{array}$ & Satun & Trang & Phang Nga \\
\hline$\overline{\text { Gulf of }}$ & Chumporn & - & & & & & \\
\hline \multirow[t]{2}{*}{ Thailand } & Surat Thani & $-0.001(0.999)$ & - & & & & \\
\hline & Nakhon Si Thammarat & $0.001(0.477)$ & $0.000(0.999)$ & - & & & \\
\hline Andaman & Satun & $0.973 *(0.000)$ & $0.979 *(0.000)$ & $0.980 *(0.000)$ & - & & \\
\hline \multirow[t]{2}{*}{ Sea } & Trang & $0.962 *(0.000)$ & $0.967 *(0.000)$ & $0.968 *(0.000)$ & $0.020(0.246)$ & - & \\
\hline & Phang Nga & $0.988 *(0.000)$ & $0.993 *(0.000)$ & $0.994 *(0.000)$ & $0.100(0.110)$ & $0.010(0.354)$ & - \\
\hline
\end{tabular}

Note: ${ }^{*}$ significant differentiation $(p<0.05): p$ values in parentheses

The third evidence, the phylogenetic tree showed two distinct lineages of haplotypes into the Gulf of Thailand population and the Andaman Sea population. The Gulf of Thailand group consisted of two haplotypes (HAP 05, HAP 06), and the Andaman Sea group was made up of four haplotypes (HAP 01, HAP 02, HAP 03, HAP 04) (Figure $2)$. The fourth evidence, the minimum spanning network was divided into two groups from a distinct pattern of geographic structure among six haplotypes (Figure 3). The Gulf of Thailand group was composed of haplotype HAP 05 and HAP 06 and connected directly by a single mutation step. The Andaman Sea group comprised four haplotypes, and haplotype HAP 01 was a central haplotype connected with other haplotypes by a single mutation step. The haplotype of the Gulf of Thailand group and the Andaman Sea group was separated by 7 mutation steps (Figure 3).

\section{Demographic history}

For the neutrality test, both Fu's $F s$ test and Tajima's $D$ test resulted were negative but not significantly from the neutral population. In Southern Thailand population, Fu's $F s$ statistic and Tajima's $D$ statistic were $-2.809(p=0.997)$ and $-1.123(p=0.936)$, in the Gulf of Thailand population were $-1.906(p=0.060)$ and $-1.068(p=0.077)$, and in the Andaman Sea population were $-1.962(p=0.128)$ and -1.041 $(p=0.132)$ (Table 6). The measurement of SSD from the goodness-of-fit test, the mismatch distribution observed from the Southern Thailand population did fit a sudden expansion model (the Southern population; $S S D=0.233$
( $p=0.073$ ), the Gulf of Thailand population; $S S D=0.001$ $(p=0.124)$, the Andaman Sea population; $S S D=0.004$ $(p=0.401)$ (Table 6, Figure 4). The raggedness statistic $(r g)$, which measured the ragged of the mismatch distribution (Harpending 1994), was not statistically significant ( $r g=0.428, p=0.055)$ in the Southern Thailand population, which was also the same in the Gulf Thailand population $(r g=0.888, p=0.901)$ and the Andaman Sea population ( $r g=0.293, p=0.590)$ (Table 6). The estimated $\theta_{l}$ was slightly higher than $\theta_{0}$ for Southern Thailand, the Gulf Thailand, and the Andaman Sea population (Table 6).

\section{Discussion \\ Genetic diversity}

Genetic diversity is an important basis for the survival of the species, in which organisms with low genetic diversity could not be able to adapt if the environment changes. Also, a low genetic diversity may result in the deterioration of the essential features for survival (Hendon 2018). The low genetic diversity of a species is influenced by many factors such as the bottleneck effect, the founder effect, inbreeding, and random genetic drift within the population (Wang et al. 2015). In our study, the genetic diversity of the hard clam population in Southern Thailand was a moderate to low level. A comparison within the genetic diversity of the hard clam $M$. lyrata population in two seas showed that the Andaman Sea population had higher genetic diversity than the Gulf of Thailand population. Interestingly, the haplotype diversity and 
nucleotide diversity were zero in two sampling sites in the Gulf of Thailand (Surat Thani and Nakhon Si Thammarat) and did not have a polymorphic site, indicating that these two populations were lost genetic diversity. In the Gulf of Thailand, the main fishing ground of hard clam M. lyrata is Surat Thani and Nakhon Si Thammarat (Fishery Statistics Analysis and Research Group 2017). Both areas were overfished by fisheries by replacing traditional fishing gear with a machine tool for commercial purposes. The overexploitation of hard clam M. lyrata in these areas may act as random genetic drift and loss of genetic diversity. Hence, the hard clam population from Surat Thani and Nakhon Si Thammarat should be focused on aid in determining populations and proper units of management for conservation. The haplotype diversity and nucleotide diversity ranged from $0.000-0.403$ and $0.00000-0.00100$, respectively. Besides, the private haplotype was a low number (private haplotype=2), indicating that the hard clam $M$. lyrata population is not responsible for retaining mutation and helps keep up high haplotype diversity within a population (Chu et al. 2012). The genetic diversity level in mtDNA COI of hard clam in Southern Thailand was lower than other bivalves such as spotted hard clam $(M$. petechialis) population in China (Wang et al. 2017b; Zheng et al. 2019), Asiatic hard clam (M. meretrix) in China and
North Korea (Li et al. 2016), Chinese venus (Cyclina sinensis) in the East China Sea (Ni et al. 2012a), and blood cockle (Tegillarca granosa) in China (Ni et al. 2012b).

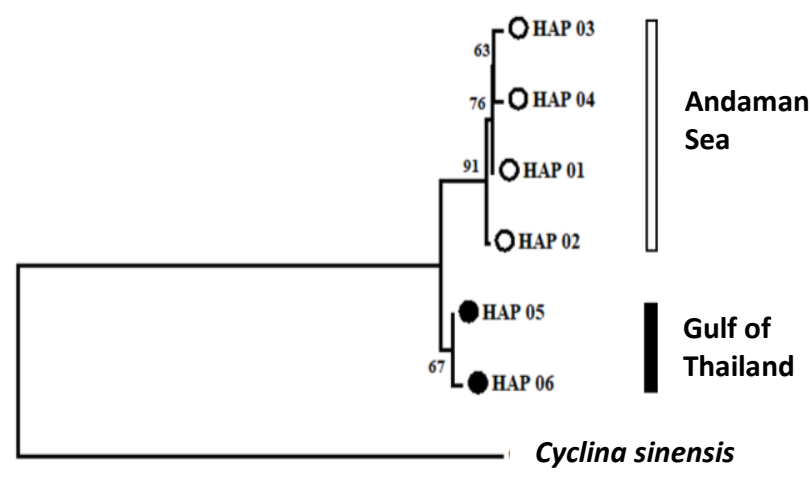

Figure 2. Neighbor-joining phylogenetic tree based on mtDNA $C O I$ of the hard clam Meretrix lyrata constructed under Kimura 2-parameter model with bootstrap value of 1000 replicates and Cyclina sinensis as outgroup

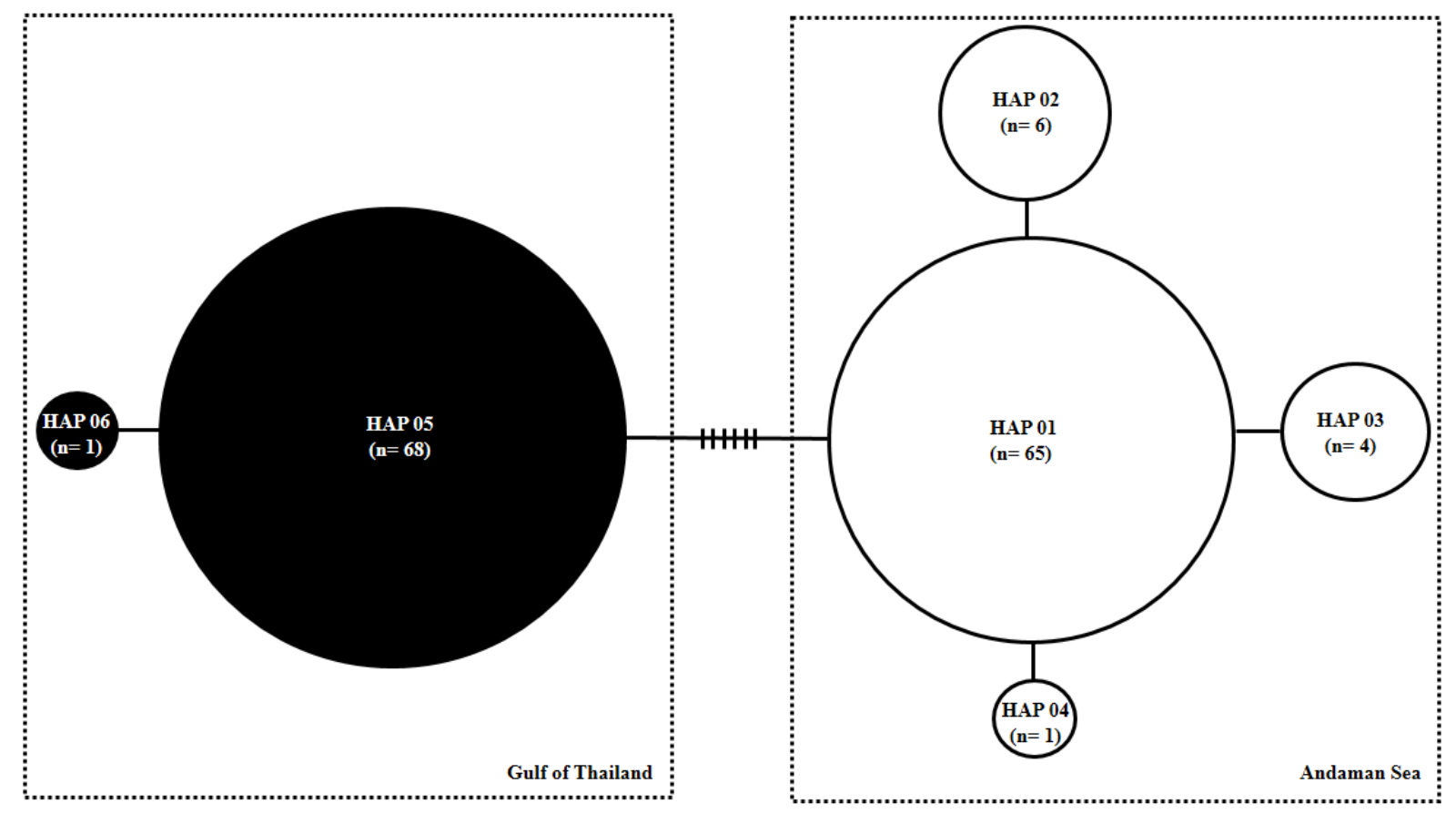

Figure 3. Minimum spanning network of the $6 \mathrm{mtDNA}$ COI haplotypes of the hard clam Meretrix lyrata. The proportion size of circle is the frequency of haplotype. White and black circles are the haplotype from the Gulf of Thailand and the Andaman Sea, respectively. The single line connecting directly to other haplotypes represents a single mutation step. The number of vertical bars on the line connecting haplotypes indicates an increasing number of mutation step

Table 6. Neutrality test and parameter indices of mismatch distribution analysis of the hard clam Meretrix lyrata 


\begin{tabular}{|c|c|c|c|c|c|c|}
\hline Collecting location & Fu's $F s$ & Tajima's $D$ & $S S D^{a}$ & $\operatorname{Rag}^{b}$ & $\theta_{0}^{c}$ & $\theta_{1}{ }^{d}$ \\
\hline Chumporn & $-0.993 *(0.007)$ & $-1.160(0.149)$ & $0.000(0.267)$ & $0.689(0.809)$ & 0.00000 & 0.09927 \\
\hline Surat Thani & 0.000 (N.A.) & $0.000(1.000)$ & $0.000(0.000)$ & $0.000(0.000)$ & 0.00000 & 0.00000 \\
\hline Nakhon Si Thammarat & 0.000 (N.A.) & $0.000(1.000)$ & $0.000(0.000)$ & $0.000(0.000)$ & 0.00000 & 0.00000 \\
\hline Satun & $-0.544(0.375)$ & $-0.094(0.750)$ & $0.253(0.134)$ & $0.272(0.230)$ & 0.90000 & 3.60000 \\
\hline Trang & $-1.635 *(0.037)$ & $-1.090(0.174)$ & $0.005(0.288)$ & $0.165(0.420)$ & 0.00527 & 99999.00000 \\
\hline Phang Nga & $-1.061(0.064)$ & $-1.157(0.141)$ & $0.000(0.254)$ & $0.712(0.820)$ & 0.00000 & 0.09053 \\
\hline Gulf of Thailand & $-1.906(0.060)$ & $-1.068(0.077)$ & $0.001(0.124)$ & $0.888(0.901)$ & 0.00000 & 0.30062 \\
\hline Andaman Sea & $-1.962(0.128)$ & $-1.041(0.132)$ & $0.004(0.401)$ & $0.293(0.590)$ & 0.00000 & 0.37510 \\
\hline Southern Thailand & $-2.809(0.997)$ & $-1.123(0.936)$ & $0.233(0.073)$ & $0.428(0.055)$ & 0.00176 & 1.67861 \\
\hline
\end{tabular}

Note: *significant differentiation $(p<0.05)$, ${ }^{\text {a }}$ sum of squared deviations, ${ }^{b}$ Raggedness index, ${ }^{c}$ population size before expansion $\left(\theta_{0}=2 N_{0} \mu\right)$, ${ }^{\mathrm{d}}$ population size after expansion $\left(\theta_{l}=2 N_{l} \mu\right), p$ values in parentheses, N.A. is not applicable.

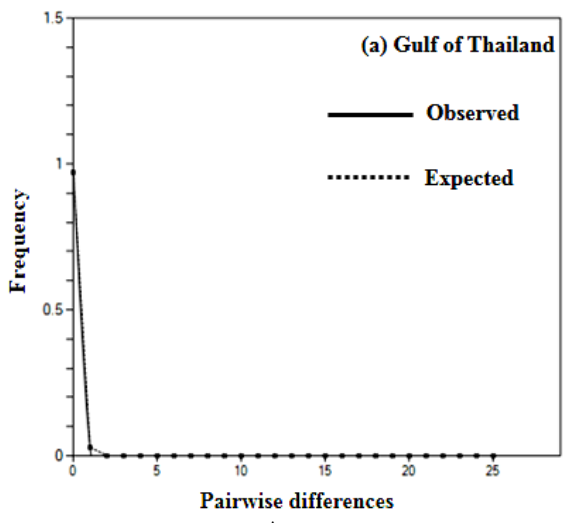

A

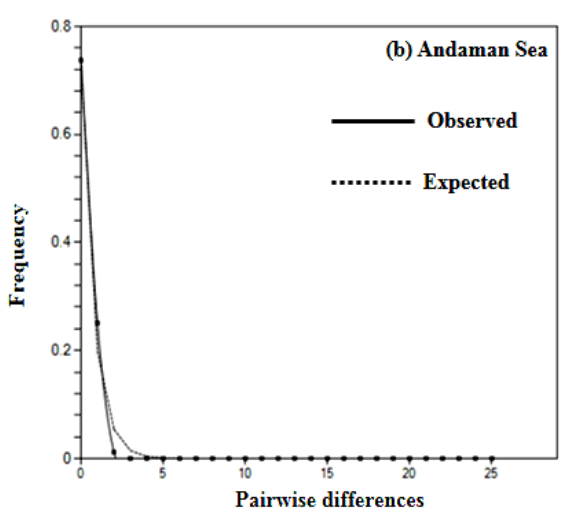

B

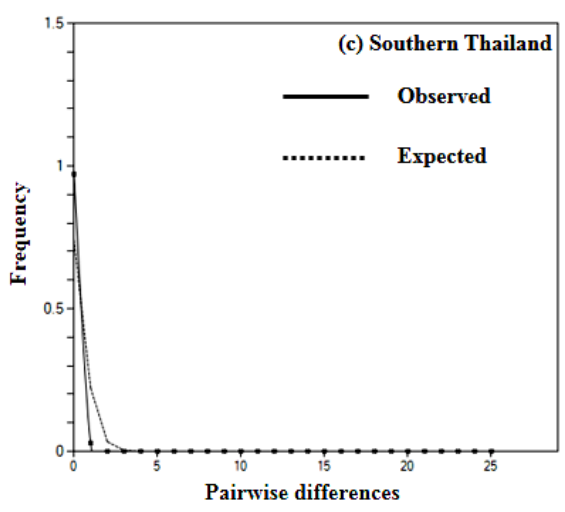

C

Figure 4. Unimodal pattern of mismatch distribution of the pairwise haplotype differences of the hard clam Meretrix lyrata. Thin line is the observed frequency and the dotted line is the expected frequency under sudden population expansion model. A. Gulf of Thailand, B. Andaman Sea, C. Southern Thailand

\section{Population genetic structure}

The study of the population genetic structure is the study of genetic changes due to various factors affecting gene frequency changes or genetic diversity, which may be caused by environmental factors, migration, or mutation (Hahn 2018). The population genetics structure indicates the survival ability of organisms, which are capable of adapting to the environment by acting in the form of genetic diversity that is appropriate for the population. The occurrence of population genetic structure is due to obstruction of the ability to gene flow in the population, such as geographic barrier or reproductive ability (Allendorf et al. 2012). In our study, the population genetic structure analysis by AMOVA, pairwise $F_{S T}$, phylogenetic tree, and minimum spanning network showed the genetic structure between the hard clam population living in the Gulf of Thailand and the Andaman Sea. Causes of genetic differences may be caused by the obstruction of gene flow from the geographic factors of the Southern region between the Gulf of Thailand and the Andaman Sea that are separated by the Thai-Malay Peninsula. Genetic differentiation between the Gulf of Thailand and the Andaman Sea has been reported in various marine species, such as littoral earthworm (Pontodrilus longissimus) (Seesamut et al. 2019), horseshoe crabs (Carcinoscorpius rotundicauda) (Obst et al. 2012), and surf clam (Paphia undulate) (Donrung et al. 2011). In this study, we suggested that the management guidelines of the hard clam $M$. lyrata population along the Southern Thailand coast should be managed as distinct units between the Gulf of Thailand and the Andaman Sea population since each population group has a separate genetic structure.

\section{Demographic history}

The study of the demographic history is the study of the changing pattern of effective population size in the last period using nucleotide sequences as a model for mutation patterns to predict changes in the past (Tajima 1989). In our study, the independent demographic history tests revealed that the hard clam living in Southern Thailand, the Gulf of Thailand, and the Andaman Sea had experienced population expansion. Firstly, the neutrality test showed negative Fu's $F s$ and Tajima's $D$ but the non-significant value indicated that the expansion of the hard clam population has been restricted to certain samplings of clam population (Rosly et al. 2013). Tajima' $D$ is very useful to investigate the nucleotide sequence is under mutation-drift equilibrium. A negative value of Tajima's $D$ indicated the population size may be increasing, expanding, or purifying selection (Korneliussen et al. 2013). Further, Fu's Fs test is 
a more powerful tool for detecting the presence of evolutionary forces resulting from a population of an excess of a new mutation and is more sensitive to population expansion (Fu 1997). A negative value of Fu's Fs statistic showed an excess number of alleles as it is expected from a recent population expansion (Korneliussen et al. 2013). Secondly, the mismatch distribution was unimodal and accepted the sudden expansion model by a goodness-of-fit test in indicating that the hard clam population had undergone a recent demographic expansion. Mismatch distribution is a collocation of the number of pairwise differences among nucleotide sequences in a sample. In an expansion population, mismatch distributions are smooth unimodal distributions that are due to the accumulation of new mutations (Grant 2015). Thirdly, the estimated values of population sizes after an expansion $\left(\theta_{1}\right)$ were higher than population sizes before an expansion $\left(\theta_{0}\right)$ in every population indicated that the hard clam population underwent population expansion. In Thailand, the population expansion in the past of other marine species has been reported such as Asiatic hard clam (M. meretrix) (Supmee et al. 2020a), blue swimming crab (Portunus pelagicus) (Supmee et al. 2020b), wedge clam (Donax scortum) (Supmee et al. 2021), and oceanic paddle crab ( $V$. litterata) (Suppapan et al 2017).

In conclusion, based on the mtDNA COI sequences results from our study showed a moderate to low genetic diversity of the hard clam M. lyrata population in Southern Thailand. Disruption of gene flow by a geographic barrier from the Thai-Malaysian peninsula causes a genetic structure between the Gulf of Thailand and the Andaman Sea population. The independent demographic history test revealed an experienced population expansion of the hard clam in Southern Thailand. However, it is necessary to use nuclear DNA markers, such as microsatellite DNA in further analysis.

\section{ACKNOWLEDGEMENTS}

The financial support of this research was fully granted by Nakhon Si Thammarat Rajabhat University, Nakhon Si Thammarat, Thailand, which we are much appreciated.

\section{REFERENCES}

Allendorf FW, Luikart GH, Aitken SN. 2012. Conservation and the Genetics of Populations. Wiley-Blackwell, New York.

Cheng J, Kao H, Dong S. 2020. Population genetic structure and gene flow of rare and endangered Tetraena mongolica Maxim. revealed by reduced representation sequencing. BMC Plant Biol 20: 391. DOI: 10.1186/s12870-020-02594-y.

Chu TJ, Wang D, Huang HL, Lin FJ, Tzeng TD. 2012. Population structure and historical demography of the whiskered velvet shrimp (Metapenaeopsis barbata) of China and Taiwan inferred from the mitochondrial control region. Zool Stud 51 (1): 99-107.

Donrung P, Tunkijjanukij S, Jarayabhand P, Poompuang S. 2011. Spatial genetic structure of the surf clam Paphia undulata in Thailand waters. Zool Stud 50 (2): 211-219.

Excoffier L, Lischer HEL. 2010. Arlequin suite ver 3.5: A new series of programs to perform population genetics analysis under Linux and Windows. Mol Ecol Resour 10 (3): 564-567. DOI: 10.1111/j.17550998.2010.02847.x.
Fishery Statistics Analysis and Research Group. 2017. Fisheries Statistics of Thailand, No. 5/2017. Department of Fisheries, Ministry of Agriculture and Cooperatives, Thailand. [Thai]

Fu FX. 1997. Statistical tests of neutrality of mutations against population growth, hitchhiking and background selection. Genetics 147: 915925.

Grant WS. 2015. Problems and cautions with sequence mismatch analysis and Bayesian skyline plots to infer historical demography. J Hered 106 (4): 333-346. DOI: 10.1093/jhered/esv020.

Guo E, Li X, Liu Y, Cheng Y, Wu CX. 2012. Genetic variation and population structure of swimming crab (Portunus trituberculatus) inferred from mitochondrial control region. Mol Biol Rep 39 (2): 1453-1463. DOI: 10.1007/s11033-011-0882-3.

Hahn MH. 2018. Molecular Population Genetics. Oxford University Press Inc, New York.

Hamli H, Idris MH, Rajaee AH, Abu Hena MK, Hoque MN. 2017. Condition index of Meretrix lyrata (Sowerby 1851) and its relationship with water parameter in Sarawak. Sains Malays 46 (4): 545-551. DOI: 10.17576/jsm-2017-4604-05

Harpending HC. 1994. Signature of ancient population growth in a lowresolution mitochondrial DNA mismatch distribution. Hum Biol 66: 591-600.

Hendon J. 2018. Advances in Conservation Genetics. Syrawood Publishing House, New York.

Idris IH, Hamli H, Abu Hena MK, Rajaee AH. 2017. Distribution of mineral contents in the selected tissues of Meretrix lyrata. J Fish Aquat Sci 12 (3): 149-156. DOI: 10.3923/jfas.2017.149.156.

Korneliussen TS, Moltke I, Albrechtsen A, Nielsen R. 2013. Calculation of Tajima's $D$ and other neutrality test statistics from low depth nextgeneration sequencing data. BMC Bioinform 14: 289.

Kumar S, Stecher G, Tamura K. 2016. MEGA7: Molecular evolutionary genetics analysis version 7.0 for bigger datasets. Mol Biol Evol 33 (7): 1870-1874. DOI: 10.1093/molbev/msw054.

Li HJ, Zhang JJ, Yuan XT, Zhang AG, Liu GZ, Shao KS. 2016. Genetic diversity and differentiation of seven geographical populations of hard clam (Meretrix meretrix) assessed by COI and microsatellite $\begin{array}{lllll}\text { markers. Acta Ecol Sin } 36 & (2) \text { 4 499-507. DOI: }\end{array}$ 10.5846/stxb201409151822.

Ma H, Ma C, Ma L. 2011. Population genetic diversity of mud crab (Scylla paramamosain) in Hainan Island of China based on mitochondrial DNA. Biochem Syst Ecol 39: 434-440. DOI: 10.1016/j.bse.2011.06.005

Ni G, Li Q, Kong L, Zheng X. 2012a. Phylogeography of bivalve Cyclina sinensis: Testing the historical glaciations and Changjiang River outflow hypotheses in northwestern Pacific. PLoS One 7: e49487. DOI: 10.1371/journal.pone.0049487

Ni G, Li Q, Kong L, Zheng X. 2012b. Phylogeography of the bivalve Tegillarca granosa in coastal China: Implications for management and conservation. Mar Ecol Prog Ser 452: 119-130. DOI: 10.3354/meps09624

Obst M, Faurby S, Bussarawit S, Funch S. 2012. Molecular phylogeny of extant horseshoe crabs (Xiphosura, Limulidae) indicates Paleogene diversification of Asian species. Mol Phylogenet Evol 62: 21-26. DOI: 10.1016/j.ympev.2011.08.025.

Rosly HAM, Mohd-Nor SA, Yahya K, Naim DM. 2013. Mitochondrial DNA diversity of mud crab Scylla olivacea (Portunidae) in Peninsular Malaysia: A preliminary assessment. Mol Biol Rep 40 (11): 64076418. DOI: 10.1007/s11033-013-2755-4.

Rozas J, Ferrer-Mata A, Sánchez-DelBarrio JC, Guirao-Rico S, Librado P, Ramos-Onsins SE, Sánchez-Gracia A. 2017. DnaSP 6: DNA sequence polymorphism analysis of large datasets. Mol Biol Evol 34 (12): 3299-3302. DOI: 10.1093/molbev/msx248.

Schlaepfer DR, Braschler B, Rusterholz HP, Baur B. 2018. Genetic effects of anthropogenic habitat fragmentation on remnant animal and plant populations: a meta-analysis. Ecosphere 9 (10): e02488. DOI: 10.1002/ecs2.2488.

Seesamut T, Jirapatrasilp P, Sutcharit C, Tongkerd P, Panha S. 2019. Mitochondrial genetic population structure and variation of the littoral earthworm Pontodrilus longissimus Seesamut and Panha, 2018 along the coast of Thailand. Eur J Soil Biol 93: 1030913. DOI: 10.1016/j.ejsobi.2019.103091.

Sukumaran S, Sebastian W, Gopalakrishnan A. 2016. Population genetic structure of Indian oil sardine, Sardinella longiceps along Indian coast. Gene 576: 372-378. DOI: 10.1016/j.gene.2015.10.043.

Supmee V, Sangthong P, Songrak A, Suppapan J. 2020a. Population genetic structure of Asiatic hard clam (Meretrix meretrix) in Thailand 
based on cytochrome oxidase subunit I gene sequence. Biodiversitas 21 (26): 2702-2709. DOI: 10.13057/biodiv/d210644.

Supmee V, Sawusdee A, Sangthong P, Suppapan J. 2020b. Population genetic structure of blue swimming crab (Portunus pelagicus) in the Gulf of Thailand. Biodiversitas 21 (9): 4260-4268. DOI: 10.13057/biodiv/d210943.

Supmee V, Songrak A, Suppapan J, Sangthong P. 2021. Population genetic structure of the wedge clam (Donax scortum) along the Andaman Sea coast of Thailand. J Fish Environ 45 (1): 85-97.

Supmee V. 2015. Population genetic structure and demographic history of spotted scat (Scatophagus argus) in Southern of Thailand. PRRJScitech 10 (2): 38-56. [Thai]

Supmee V, Suppapan J. 2020. Genetic diversity of threadfin bream (Nemipterus hexodon) in lower part of Southern Thailand. PRRJScitech 15 (1): 41-55. [Thai]

Suppapan J, Pechsiri J, O-Thong S, Vanichanon A, Sangthong P, Supmee V. 2017. Population genetic analysis of oceanic paddle crab (Varuna litterata) in Thailand. Sains Malaysiana 46 (12): 2251-2261. DOI: 10.17576/jsm-2017-4612-01.

Tajima F. 1989. Statistical method for testing the neutral mutation hypothesis by DNA polymorphism. Genetics 123 (3): 585-595.

Thompson JD, Higgins DG, Gibson TJ. 1994. CLUSTALW: Improving the sensitivity of progressive multiple sequence alignment through sequence weighting, position-specific gap penalties and weight matrix choice. Nucleic Acids Res 22 (22): 4673-4680. DOI: 10.1093/nar/22.22.4673
Wang J, Zhang FY, Jiang KJ, Ma CY, Song W, Lin N, Jiang YZ, Li SF, Cheng JH, Ma LB. 2015. Genetic diversity of Portunus trituberculatus based on the mitochondrial cytochrome oxidase subunit I sequence from the East China Sea. Mar Fish 37 (2): 114121.

Wang W, Ma C, Chen W, Zhang H, Kang W, Ni Y, Ma L. 2017a. Population genetic diversity of Chinese sea bass (Lateolabrax maculatus) from southeast coastal regions of China based on mitochondrial COI gene sequences. Biochem Syst Ecol 71: 114-120. DOI: $10.1016 /$ j.bse.2017.01.002

Wang X, Kong L, Chen J, Matsukuma A, Li Q. 2017b. Phylogeography of bivalve Meretrix petechialis in the Northwestern Pacific indicated by mitochondrial and nuclear DNA data. PLoS ONE 12 (8): e0183221. DOI: 10.1371/journal.pone.0183221.

Zarei F, Alipanah H. 2014. Mitochondrial DNA variation, genetic structure and demographic history of Iranian populations. Mol Biol Res Commun 3 (1): 45-65.

Zhang Y, Yang F, Wang Z, You Q, Lou B, Xu D, Chen R, Zhan W, Liu F. 2017. Mitochondrial DNA variation and population genetic structure in the small yellow croaker at the coast of Yellow Sea and East China Sea. Biochem Syst Ecol 71: 236-243. DOI: 10.1016/j.bse.2017.03.003.

Zheng J, Nie H, Yang F, Yan X. 2019. Genetic variation and population structure of different geographical populations of Meretrix petechialis based on mitochondrial gene COI. J Genet 98 (3): 68. DOI: 10.1007/s12041-019-1111-4. 